DOI: https://doi.org/10.15688/mpcm.jvolsu.2021.3.2

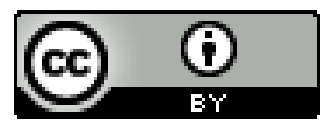

UDC 51-71,51-73

Submitted: 09.03.2021

LBC 22.161 .2

Accepted: 30.07.2021

\title{
EXACT SOLUTIONS \\ OF THE GENERALIZED NONLINEAR SCHRODINGER EQUATION ${ }^{1}$
}

\author{
Gaukhar N. Shaikhova \\ PhD, Associate Professor, Department of General and Theoretical Physics, \\ L.N. Gumilyov Eurasian National University \\ g.shaikhova@gmail.com \\ https://orcid.org/0000-0002-0819-5338 \\ K. Munaitpasova St, 22, 010008 Nur-Sultan, Kazakhstan
}

\section{Arailym M. Syzdykova}

Senior Lecturer, Department of General and Theoretical Physics, L.N. Gumilyov Eurasian National University syzdykova’am@mail.ru

K. Munaitpasova St, 22, 010008 Nur-Sultan, Kazakhstan

\section{Samgar Daulet}

Student, Department of General and Theoretical Physics, L.N. Gumilyov Eurasian National University samgar.daulet@mail.ru K. Munaitpasova St, 22, 010008 Nur-Sultan, Kazakhstan

Abstract. In this work, the generalized nonlinear Schrodinger equation is investigated. Exact solutions are derived by the sine-cosine method. This method is used to obtain the exact solutions for different types of nonlinear partial differential equations. Graphs of obtained solutions are presented. The obtained solutions are found to be important for the explanation of some practical physical problems.

Key words: generalized nonlinear Schrodinger equation, ODE, PDE, sinecosine method, exact solution. 


\section{Introduction}

The study exact solutions for nonlinear partial differential equations play an important role in many phenomena in physics such as hydrodynamics, fluid mechanics, condensed matter physics, plasma physics, optics and so on. Many effective and powerful methods have been established and improved, such as the Jacobi elliptic method [6], the $\left(G_{0} / G\right)$ expansion method [4], the Exp-function method [5], the tanh-function method [7], the Darboux transformation method [3].

In this work we study the generalized nonlinear Schrodinger equation,

$$
q_{z}=i\left(q_{t t}+2|q|^{2} q+\alpha q\right)+\gamma q_{t}
$$

where $q$ is a complex valued function of the spatial coordinate $z$ and the time $t$, the subscripts denote the partial derivatives with respect to the variables $z, t$. The equation (1) is a typical soliton equation with rich physical and mathematical applications where $\alpha$ denotes the amplification or absorption and $\gamma$ relates to the group velocity $[1 ; 2]$.

The aim of this paper is to construct some new exact solutions for equation (1). We study the equation (1) by the sine-cosine method that have been extensively studied and widely applied for a wide variety of nonlinear problems [8-10].

The paper is organized as follows. In Section 2, we present the description of sinecosine method. In Section 3, the sine-cosine method is applied to obtain exact solutions for generalized nonlinear Schrodinger equation.

\section{Description of Sine-cosine Method}

In this section we describe the sine-cosine method [8-10]. According to the sine-cosine method by using a wave variable

$$
u(z, t)=u(z-c t)
$$

the partial differential equation (PDE)

$$
E_{1}\left(u, u_{t}, u_{z}, u_{z z}, u_{z z z}, \ldots\right)=0
$$

can be converted to ordinary differential equation (ODE)

$$
E_{2}\left(u,-c u^{\prime}, u^{\prime}, u^{\prime \prime}, u^{\prime \prime \prime}, \ldots\right)=0 .
$$

So, one can immediately reduce the one-dimensional PDE (3) into ODE (4) by transformation (2). Then the equation (4) is integrated as long as all terms contain derivatives where integration constants are considered zeros. The solutions of ODE (4) can be expressed in the form

$$
u(z, t)=\lambda \cos ^{\beta}(\mu \xi),|\xi| \leq \frac{\pi}{2 \mu},
$$

or

$$
u(z, t)=\lambda \sin ^{\beta}(\mu \xi),|\xi| \leq \frac{\pi}{\mu},
$$


where $\xi=z-c t$ and the parameters $\lambda, \mu$ and $\beta$ will be determined, and $\mu$ is wave number and $c$ is wave speed respectively. The derivatives of (5) become

$$
\begin{aligned}
\left(u^{n}\right)^{\prime} & =-n \beta \mu \lambda^{n} \cos ^{n \beta-1}(\mu \xi) \sin (\mu \xi), \\
\left(u^{n}\right)^{\prime \prime} & =-n^{2} \mu^{2} \beta^{2} \lambda^{n} \cos ^{n \beta}(\mu \xi)+n \mu^{2} \lambda^{n} \beta(n \beta-1) \cos ^{n \beta-2}(\mu \xi) .
\end{aligned}
$$

And the derivatives of (6) have next forms

$$
\begin{aligned}
\left(u^{n}\right)^{\prime} & =-n \beta \mu \lambda^{n} \sin ^{n \beta-1}(\mu \xi) \cos (\mu \xi), \\
\left(u^{n}\right)^{\prime \prime} & =-n^{2} \mu^{2} \beta^{2} \lambda^{n} \sin ^{n \beta}(\mu \xi)+n \mu^{2} \lambda^{n} \beta(n \beta-1) \sin ^{n \beta-2}(\mu \xi),
\end{aligned}
$$

and so on for the other derivatives. Applying (5)-(10) into the reduced ODE (4) we obtain a trigonometric equation of $\cos ^{\beta}(\mu \xi)$ or $\sin ^{\beta}(\mu \xi)$ terms. Then, we determine the parameters by first balancing the exponents of each pair of cosine or sine to determine $\beta$. Next, we collect all coefficients of the same power in $\cos ^{k}(\mu \xi)$ or $\sin ^{k}(\mu \xi)$, where these coefficients have to vanish. The system of algebraic equations among the unknown $\beta, \lambda$, and $\mu$ will be given and from that we can determine coefficients.

\section{Using the Sine-cosine Method}

We consider the generalized nonlinear Schrodinger equation (1). By transformation

$$
q=e^{i(a z+d t)} u(z, t),
$$

the equation (1) can be converted to

$$
i a u+u_{z}+i d^{2} u+2 d u_{t}-i u_{t t}-2 i u^{3}-i \alpha u-i d \gamma u-\gamma u_{t}=0,
$$

Be separating real and imaginary parts in the equation (12) we obtain next system

$$
\begin{aligned}
u_{z}+2 d u_{t}-\gamma u_{t} & =0, \\
u\left(a+d^{2}-\alpha-\gamma d\right)-u_{t t}-2 u^{3} & =0 .
\end{aligned}
$$

Substituting the wave transformation

$$
u(z, t)=u(\xi)=u(z-c t),
$$

into system of equations (13)-(14) we obtain that

$$
\begin{aligned}
u^{\prime}(1-2 d c+\gamma c) & =0, \\
u\left(a+d^{2}-\alpha-\gamma d\right)-c^{2} u^{\prime \prime}-2 u^{3} & =0 .
\end{aligned}
$$

From equation (16) we can get

$$
c=\frac{1}{2 d-\gamma} \text {. }
$$

So, finally we study ODE (17)

$$
u\left(a+d^{2}-\alpha-\gamma d\right)-c^{2} u^{\prime \prime}-2 u^{3}=0,
$$

where $c$ is expressed by equation (18). 


\subsection{The Sine Solution}

According to method the sine solution of the (19) can be found by transformation

$$
u=\lambda \sin ^{\beta}(\mu \xi) .
$$

We use (20) and its second order derivative

$$
u^{\prime \prime}=-\mu^{2} \beta^{2} \lambda \sin ^{\beta}(\mu \xi)+\mu^{2} \lambda \beta(\beta-1) \sin ^{\beta-2}(\mu \xi),
$$

and substitute (20) and (21) into (19) we obtain

$$
\begin{array}{r}
\lambda \sin ^{\beta}(\mu \xi)\left(a+d^{2}-\alpha-\gamma d\right)+c^{2} \mu^{2} \beta^{2} \lambda \sin ^{\beta}(\mu \xi)- \\
-c^{2} \mu^{2} \lambda \beta(\beta-1) \sin ^{\beta-2}(\mu \xi)-2 \lambda^{3} \sin ^{3 \beta}(\mu \xi)=0 .
\end{array}
$$

From (22) we find $\beta$ :

$$
\beta-2=3 \beta \Rightarrow \beta=-1 \text {. }
$$

Substitute (23) in (22) we obtain equation

$$
\begin{array}{r}
\lambda \sin ^{-1}(\mu \xi)\left(a+d^{2}-\alpha-\gamma d\right)+c^{2} \mu^{2} \lambda \sin ^{-1}(\mu \xi)- \\
-2 c^{2} \mu^{2} \lambda \sin ^{-3}(\mu \xi)-2 \lambda^{3} \sin ^{-3}(\mu \xi)=0 .
\end{array}
$$

From the equation (24) we have the next system

$$
\begin{aligned}
& \sin ^{-1}(\mu \xi): \lambda\left(a+d^{2}-\alpha-\gamma d\right)+c^{2} \mu^{2} \lambda=0, \\
& \sin ^{-3}(\mu \xi):-2 c^{2} \mu^{2} \lambda-2 \lambda^{3}=0 .
\end{aligned}
$$

The equation (25) gives

$$
\mu= \pm \frac{\sqrt{-\left(a+d^{2}-\alpha-\gamma d\right)}}{c}
$$

and from (26) we obtain

$$
\lambda= \pm \sqrt{\left(a+d^{2}-\alpha-\gamma d\right)} .
$$

Substituting (27)-(28) into (20) and then obtained expression into (11) we have the sine solution

$$
q_{1}(z, t)= \pm e^{i(a z+d t)} \sqrt{a-d^{2}-\alpha-\gamma d} \sin ^{-1}\left(\frac{\sqrt{-\left(a+d^{2}-\alpha-\gamma d\right)}}{c}(z-c t)\right)
$$

where $c=\frac{1}{2 d-\gamma}$. 


\subsection{The Cosine Solution}

Cosine solution of the (19) can be found by transformation

$$
u=\lambda \cos ^{\beta}(\mu \xi),
$$

and its second order derivative is

$$
u^{\prime \prime}=-\mu^{2} \beta^{2} \lambda \cos ^{\beta}(\mu \xi)+\mu^{2} \lambda \beta(\beta-1) \cos ^{\beta-2}(\mu \xi) .
$$

Substitute (30) and (31) into (19) we obtain

$$
\begin{array}{r}
\lambda \cos ^{\beta}(\mu \xi)\left(a+d^{2}-\alpha-\gamma d\right)+c^{2} \mu^{2} \beta^{2} \lambda \cos ^{\beta}(\mu \xi)- \\
-c^{2} \mu^{2} \lambda \beta(\beta-1) \cos ^{\beta-2}(\mu \xi)-2 \lambda^{3} \cos ^{3 \beta}(\mu \xi)=0 .
\end{array}
$$

From (32) we find $\beta$ :

$$
\beta-2=3 \beta \Rightarrow \beta=-1
$$

Substitute (33) in (32) we obtain

$$
\begin{array}{r}
\lambda \cos ^{-1}(\mu \xi)\left(a+d^{2}-\alpha-\gamma d\right)+c^{2} \mu^{2} \lambda \cos ^{-1}(\mu \xi)- \\
-2 c^{2} \mu^{2} \lambda \cos ^{-3}(\mu \xi)-2 \lambda^{3} \cos ^{-3}(\mu \xi)=0 .
\end{array}
$$

From the equation (34) we have the next system

$$
\begin{array}{ll}
\cos ^{-1}(\mu \xi) & : \lambda\left(a+d^{2}-\alpha-\gamma d\right)+c^{2} \mu^{2} \lambda=0, \\
\cos ^{-3}(\mu \xi): & -2 c^{2} \mu^{2} \lambda-2 \lambda^{3}=0 .
\end{array}
$$

From (35) we have

$$
\mu= \pm \frac{\sqrt{-\left(a+d^{2}-\alpha-\gamma d\right)}}{c}
$$

and from (36) we obtain

$$
\lambda= \pm \sqrt{\left(a+d^{2}-\alpha-\gamma d\right)} .
$$

Substituting (37)-(38) into (30) and then obtained expression into (11) we obtain the cosine solution

$$
q_{2}(z, t)= \pm e^{i(a z+d t)} \sqrt{a-d^{2}-\alpha-\gamma d} \cos ^{-1}\left(\frac{\sqrt{-\left(a+d^{2}-\alpha-\gamma d\right)}}{c}(z-c t)\right)
$$

where $c=\frac{1}{2 d-\gamma}$.

In Figures 1, 2 and 3, we show the profile of solutions (29) and (39) with three cases: $\alpha=\gamma ; \alpha<\gamma ; e \alpha>\gamma$. 

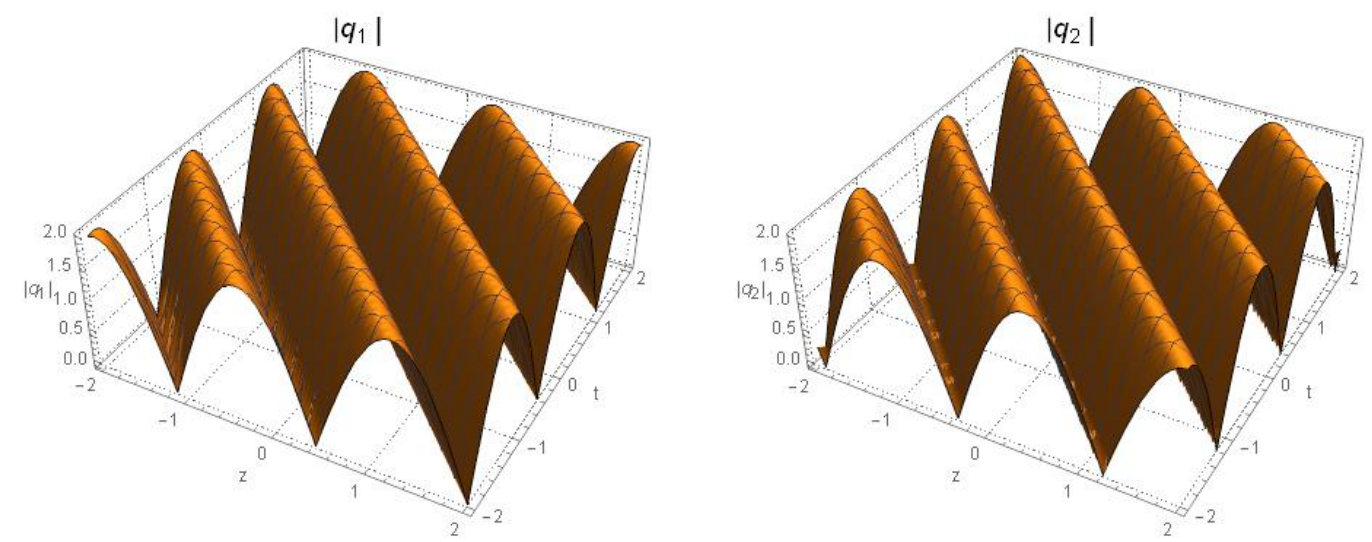

Fig. 1. Solutions of $q_{1}(z, t)$ and $q_{2}(z, t)$ in case $\alpha=\gamma$.

The parameters adopted here are: $a=1 ; d=1 ; \alpha=3 ; \gamma=3$
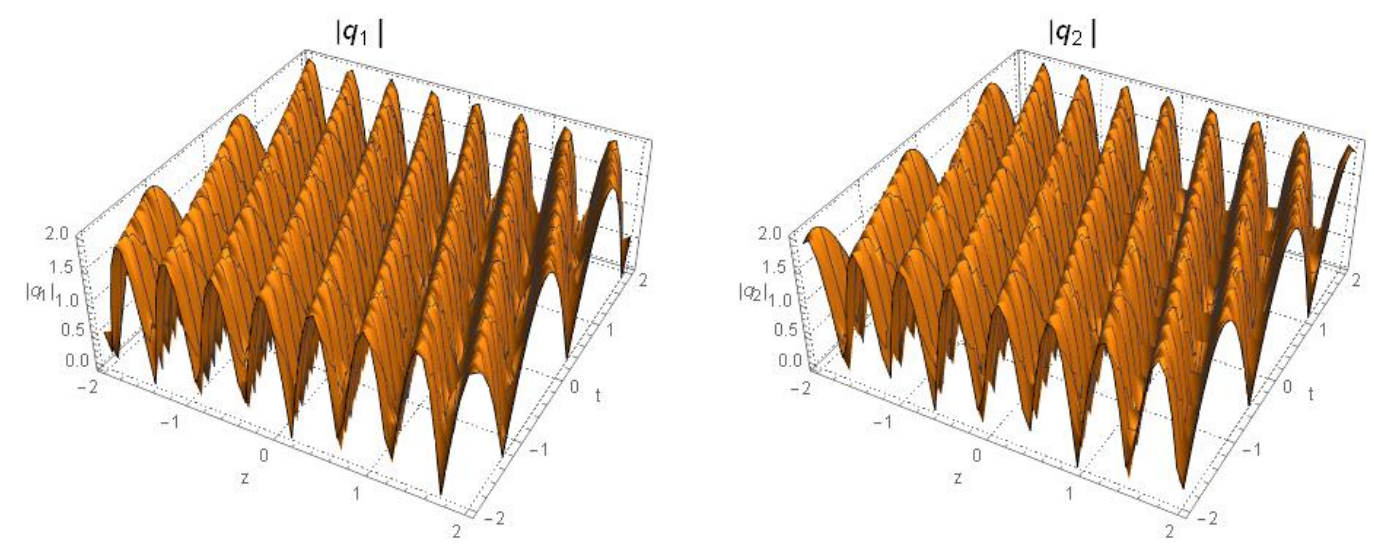

Fig. 2. Solutions of $q_{1}(z, t)$ and $q_{2}(z, t)$ in case $\alpha<\gamma$.

The parameters adopted here are: $a=1 ; d=1 ; \alpha=1 ; \gamma=5$
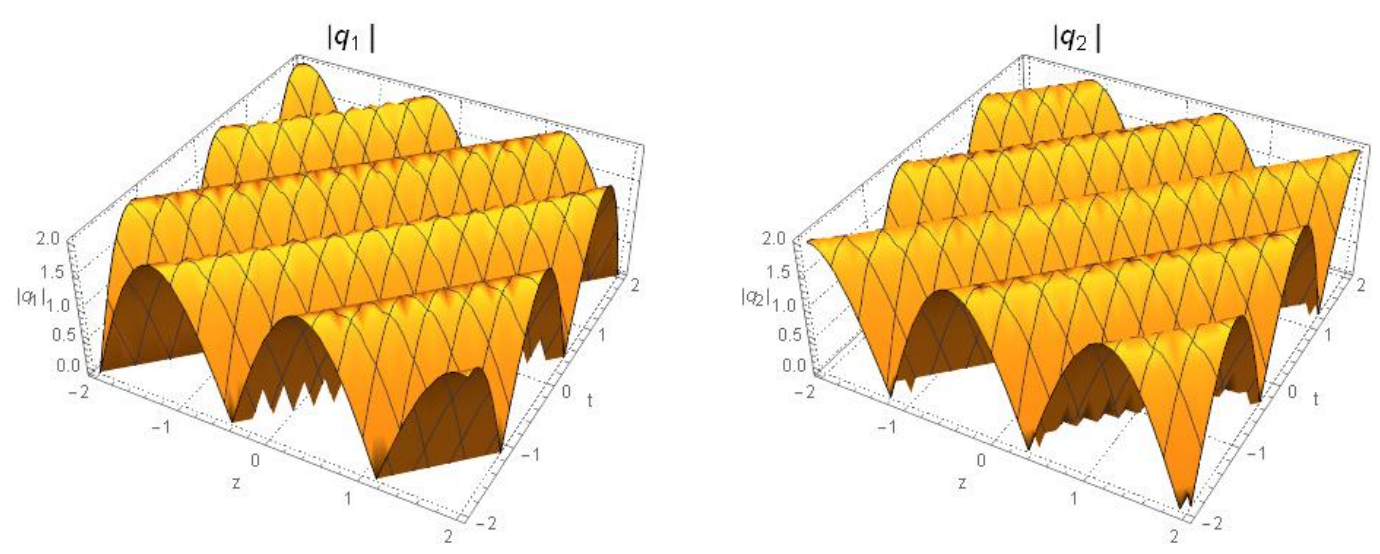

Fig. 3. Solutions of $q_{1}(z, t)$ and $q_{2}(z, t)$ in case $\alpha>\gamma$.

The parameters adopted here are: $a=1 ; d=1 ; \alpha=5 ; \gamma=1$ 


\section{Conclusion}

In this work the sine-cosine method was used to present an analytic study of the generalized nonlinear Schrodinger equation. Several exact solutions were obtained. The plots of obtained solutions are presented for cases $\alpha=\gamma ; \alpha<\gamma$; e $\alpha>\gamma$. The performance of the scheme shows that the method is powerful and reliable. The present method is readily applicable to a large variety of such nonlinear equations.

\section{NOTE}

${ }^{1}$ This research is funded by the Science Committee of the Ministry of Education and Science of the Republic of Kazakhstan (Grant No. AP09057947).

\section{REFERENCES} $467 \mathrm{p}$

1. Agrawal G.P. Nonlinear Fiber Optics. San Diego, Academic Press, 2001.

2. Allen L., Eberly J.H. Optical Resonance and Two-Level Atoms. New York, Wiley Press, 1975. xiii +233 p.

3. Bekova G., Yesmakhanova K., Myrzakulov R., Shaikhova G. Darboux Transformation and Soliton Solution for the (2+1)-Dimensional Complex Modifed Korteweg-de Vries Equations. J.Phys.: Conference Series, 2017, vol. 54, no. 936, article ID: 012045.

4. Feng J., Li W., Wan Q. Using $\left(G_{0} / G\right)$-Expansion Method to Seek Traveling Wave Solution of Kolmogorov - Petrovskii - Piskunov Equation. Appl. Math. Comput, 2011, no. 217, pp. 5860-5865.

5. He J., Wu X. Exp-Function Method for Nonlinear Wave Equations. Chaos, Solitons \& Fractals, 2006, vol. 30, pp. 700-708.

6. Inc M., Ergut M. Periodic Wave Solutions for the Generalized Shallow Water Wave Equation by the Improved Jacobi Elliptic Function Method. Appl. Math. E-Notes, 2005, no. 5, pp. 89-96.

7. Malfliet W. The Tanh method. II. Perturbation Technique for Conservative Systems. Phys. Scr., 1996, vol. 54, pp. 569-575.

8. Wazwaz A.M. A Sine-Cosine Method for Handling Nonlinear Wave Equations. Math. Comput. Modelling, 2004, vol. 40 (5-6), pp. 499-508.

9. Wazwaz A.M. The Sine-Cosine Method for Obtaining Solutions with Compact and Noncompact Structures. Appl. Math. Comput, 2004, vol. 159 (2), pp. 559-576.

10. Wazwaz A.M. Solitons and Periodic Solutions of Coupled Nonlinear Evolution Equations by Using Sine-Cosine Method. Internat. J. Comput. Math, 2006, vol. 83 (12), pp. 915924.

\section{ТОЧНЫЕ РЕШЕНИЯ ОБОБЩЕННОГО НЕЛИНЕЙНОГО УРАВНЕНИЯ ШРЕДИНГЕРА}

\section{Гаухар Нурлыбековна Шайхова}

Доктор (PhD), доцент кафедры общей и теоретической физики, Евразийский национальный университет им. Л.Н. Гумилева g.shaikhova@gmail.com https://orcid.org/0000-0002-0819-5338

ул. К. Мунайтпасова, 22, 010008 г. Нур-султан, Казахстан 


\section{Арайлым Мерекеновна Сыздыкова}

Старший преподаватель кафедры общей и теоретической физики, Евразийский национальный университет им. Л.Н. Гумилева syzdykova_am@mail.ru

ул. К. Мунайтпасова, 22, 010008 г. Нур-султан, Казахстан

\section{Самгар Даулет}

Студент кафедры общей и теоретической физики, Евразийский национальный университет им. Л.Н. Гумилева samgar.daulet@mail.ru

ул. К. Мунайтпасова, 22, 010008 г. Нур-султан, Казахстан

Аннотация. В работе исследуется обобщенное нелинейное уравнение Шредингера. Точные решения получены методом синус-косинусов. Этот метод используется для получения точных решений для различных типов нелинейных уравнений в частных производных. Представлены графики полученных решений. Полученные решения важны для объяснения некоторых задач физики.

Ключевые слова: обобщенное нелинейное уравнение Шредингера, ОДУ, ДУЧП, метод синус-косинусов, точное решение.

ISSN 2587-6325. Математ. физика и компьютер. моделирование. 2021. T. 24. № 3 